\title{
Regulation of Cellulase Production by Myrothecium verrucaria Grown on Non-cellulosic Substrates
}

\author{
By M. A. HULME AND D. W. STRANKS \\ Department of Fisheries and Forestry, Canadian Forestry Service, \\ Forest Products Laboratory, Ottawa, Canada \\ (Accepted for publication I6 August I97I)
}

\begin{abstract}
SUMMAR Y
Myrothecium verrucaria can produce cellulase when grown on media containing glucose or glycerol as sole carbohydrate source. The enzyme complex can depolymerize cellulosic substrates ranging from carboxymethylcellulose to cotton fibres. Hemicellulase is also produced. These depolymerases are first detected intracellularly near the time of the deceleration phase of growth and appear extracellularly a few hours later. Since cellulase can be produced by reducing the organism's growth rate in the absence of cellulose or any of its constituent sugars, it is suggested that this enzyme is constitutive and that production may be partly controlled by catabolite repression.
\end{abstract}

\section{INTRODUCTION}

Cellulolytic fungi cause extensive damage to all types of cellulosic materials ranging from textiles to timber. Depolymerases appear to mediate this destruction but their mechanism of production remains obscure. Earlier workers suggested that production of the main depolymerase, cellulase, was induced by cellobiose formed from cellulose (Mandels \& Reese, 1960) but we have shown that the enzyme can also be obtained merely by reducing the growth rate of the fungus irrespective of the carbohydrate source in the medium (Hulme \& Stranks, 1970). Other workers have extended our findings with fungi by using the cellulolytic bacterium Pseudomonas fluorescens (Yamane, Suzuki, Hirotani, Ozawa \& Nisizawa, I970) to demonstrate similar control of production of cellulase and they also concluded that the enzyme was apparently constitutive. This paper gives further details of the regulatory mechanism and also shows that the enzyme formed on simple carbon sources possesses all the components necessary for depolymerizing the cellulose of cotton fibres. Myrothecium verrucaria was used in this investigation even though Trichoderma viride is reported to produce a more potent cellulase (Mandels \& Reese, 1964), because sophorose, an impurity in reagent glucose, stimulates cellulase production in some strains of the latter organism (Mandels, Parrish \& Reese, 1962) and might thus be considered to invalidate our conclusions.

\section{METHODS}

Organism. Myrothecium verrucaria (Alb. and Schw.) Ditm. ex Fr. was obtained from the American Type Culture Collection as ATCC 9095.

Culture conditions. Stock cultures were maintained on $2 \%(\mathrm{w} / \mathrm{v})$ malt agar slants at $4^{\circ}$ and subcultured every 6 months. Liquid culture media were generally formulated according to Reese \& Mandels (I966) but with $\mathrm{NaNO}_{3}$ substituted for $\left(\mathrm{NH}_{4}\right)_{2} \mathrm{SO}_{4}$ to diminish the rapid $\mathrm{pH}$ drop that always occurred as the ammonium salt was consumed. The basal 
medium (minus carbohydrate) comprised per litre: $\mathrm{NaNO}_{3}, \mathrm{I} \cdot 8 \mathrm{~g} . ; \mathrm{KH}_{2} \mathrm{PO}_{4}, 2 \cdot 0 \mathrm{~g}$.; urea, $0.3 \mathrm{~g} . ; \mathrm{MgSO}_{4} \cdot 7 \mathrm{H}_{2} \mathrm{O}, 0.3 \mathrm{~g}$. $; \mathrm{CaCl}_{2}, 0.3 \mathrm{~g}$; yeast extract, 0.I g.; $\mathrm{FeSO}_{4} \cdot 7 \mathrm{H}_{2} \mathrm{O}, 5 \mathrm{mg}$.; $\mathrm{MnSO}_{4} \cdot \mathrm{H}_{2} \mathrm{O}, 2 \mathrm{mg}$.; $\mathrm{CoCl}_{2}, 2 \mathrm{mg}$.; $\mathrm{ZnCl}_{2}, \mathrm{I} \cdot 8 \mathrm{mg}$. Only highest purity reagents were used. The $\mathrm{pH}$ before autoclaving was 4.6 and was not adjusted.

Inocula were grown at $28^{\circ}$ on a gyrotary shaker (I50 rev./min.; 3 in. rotary throw) in $250 \mathrm{ml}$. Erlenmeyer flasks containing $80 \mathrm{ml}$. of basal medium supplemented with $\mathrm{I} \%(\mathrm{w} / \mathrm{v})$ carbohydrate. About $2 \mathrm{ml}$. of sterile distilled water was added to a 7-day slant and the resulting spore suspension transferred to two shake flasks. After 2 days when the mycelial dry weight reached approximately $250 \mathrm{mg}$./flask, and before the carbohydrate was totally consumed, the mycelium was washed with sterile distilled water $(3 \times 80 \mathrm{ml}$.), blended for I min. in a Waring blender and samples used to inoculate shake-culture flasks, or the entire flask contents used to inoculate a fermenter.

Batch-culture experiments were performed in shake flasks under the same conditions used for inoculum preparation. Experiments employing a continuous feed of substrate were performed at $28^{\circ}$ in a New Brunswick 41 . glass fermenter modified by the addition of a side-arm overflow at the $3 \cdot 31$. level. The same basal medium supplemented by a low concentration of carbohydrate was used, and when the latter was nearly exhausted a gravity feed of basal medium containing a suitable concentration of the same carbohydrate was started. The flow into the fermenter was restricted by inclusion of glass capillary tubing in the line and the required feed rate obtained by raising or lowering the 61 . reservoir containing 41 . of medium. Feed rate was maintained constant by operating the feed reservoir as a simple Mariotte flask, taking suitable precautions to ensure asepsis. The overflow from the fermenter was collected in a 41 . sterile receiver using a slight vacuum if necessary to reduce mycelial growth in the line.

Measurement of growth. Mycelium from a known volume of medium was filtered through tared Whatman no. I filter paper, washed with distilled water, dried in vacuo at $50^{\circ}$ for $3 \mathrm{~h}$. and weighed.

Determination of carbohydrate content of medium. Glucose was assayed by the volumetric method of Somogyi (1952), the limit of detection being $0.01 \mathrm{mg}$. glucose/ml. culture. Glycerol was assayed according to Neish (1952) with some modifications by determining the amount of formic acid produced from oxidation with periodate: a 2 to $25 \mathrm{ml}$. sample of culture supernatant was made up to $40 \mathrm{ml}$. with water, adjusted to $\mathrm{pH} 5.5$ with $\mathrm{N} / \mathrm{IO}$ $\mathrm{NaOH}$, and Io $\mathrm{ml}$. $\mathrm{NaIO}_{4}$ solution (O.I M, pH 5.5) added. After I to $3 \mathrm{~h}$. at room temperature $5 \mathrm{ml}$. of $10 \%(\mathrm{v} / \mathrm{v}) 2,3$-butanediol solution was added to convert excess periodate to iodate and $10 \mathrm{~min}$. later the formic acid formed from glycerol was titrated with $\mathrm{N} / \mathrm{IO} \mathrm{NaOH}$ to $\mathrm{pH} 5.5$. The limit of detection was $0.05 \mathrm{mg}$. glycerol $/ \mathrm{ml}$. culture.

Enzyme assays. Cellulase activity denotes the depolymerization of all types of cellulosic materials (King \& Vessal, 1969). In most of this work cellulase was determined viscometrically as carboxymethylcellulase ( $\beta$-I,4-glucan 4-glucanohydrolase; EC. 3.2.I.4) because this provided a rapid and sensitive method for detecting cleavage of $\beta$-I,4glucosidic bonds. Ability to depolymerize other types of cellulose including cotton fibres was demonstrated separately in later tests.

\section{Carboxymethylcellulase (CM-cellulase)}

Depolymerization of carboxymethylcellulose was assayed viscometrically at $40^{\circ}$, and units per volume of undiluted enzyme used for assay are defined in terms of the decrease in seconds of efflux time of the incubation mixture per elapsed minute of incubation in standard conditions. The sodium carboxymethylcellulose used was manufactured by 
Hercules Powder Co., Wilmington, Delaware as type $7 \mathrm{~L}$ with a degree of substitution of 0.7 and average molecular weight of 70,000; a solution was prepared by dissolving $5 \mathrm{~g}$. of polymer in I 1 . of $\mathrm{pH} 5.0$ acetate buffer $(0.05 \mathrm{M})$, filtering through M-porosity sintered glass to remove gel particles, freezing to $-70^{\circ}$ for $5 \mathrm{~min}$. and finally thawing and boiling under reflux for Io min. Polymer solutions were normally frozen before storage. Culture broth which contained the test enzyme was filtered through M-porosity sintered glass and $3 \mathrm{ml}$. filtrate was mixed with $10 \mathrm{ml}$. carboxymethylcellulose solution at $40^{\circ}$ before pouring into a no. I Ubbelöhde viscometer. A determination of the efflux time of the mixture was started exactly $5 \mathrm{~min}$. after mixing and repeated during subsequent $5 \mathrm{~min}$. periods until four readings had been obtained. The difference between successive readings of efflux time was adjusted to about $2 \mathrm{sec}$. by using supernatant diluted with water where necessary; the efflux time for the first reading was then about $\mathrm{I} 45 \mathrm{sec}$. The efflux time for buffer was $66.6 \mathrm{sec}$. Enzyme units are generally defined empirically in terms of the rate of increase of reciprocal of specific viscosity, $\eta_{\mathrm{gp}}$, and it has been shown (M. A. Hulme, unpublished results) that this relationship can also be used to calculate standard international units of enzyme. However, relative units can be calculated satisfactorily by the present method because when time, $t$, is small

$$
\frac{\mathrm{d}}{\mathrm{d} t}\left(\frac{\mathrm{I}}{\eta_{\mathrm{sp}}}\right)=\frac{\eta_{\mathrm{sp1}}-\eta_{\mathrm{sp}} 2}{\eta_{\mathrm{sp} 1} \times \eta_{\mathrm{sp} 2}} \times \frac{\mathrm{I}}{t}
$$

and since changes in specific viscosity are small in present conditions, changes in the magnitude of the above equation will mainly be given by changes in the numerator. For instance, in present conditions if $\eta_{\mathrm{pp} 1}$ is constant then ratios of relative and standard units will agree within I $\%$ and even if $\eta_{\mathrm{spl}}$ varies by as much as $5 \mathrm{sec}$., which is very unusual, agreement will still be within $10 \%$.

\section{Cellulase using cotton as substrate}

Sixty-mesh nonabsorbent cotton (Fisher Scientific Co., Montreal, Quebec) was dewaxed according to Halliwell (1957) and final traces of water were removed by freeze-drying. For assay, about $2 \mathrm{mg}$. cotton was weighed to the nearest I $\mu \mathrm{g}$. into equilibrated $15 \mathrm{ml}$. centrifuge tubes graduated at $\mathrm{I} \cdot 8 \mathrm{ml}$. following the procedure of Wood (I969). Then I.5 ml. of $0.2 \mathrm{M}$ sodium acetate buffer was added together with $0 . \mathrm{I} \mathrm{ml}$. of $0.5 \mathrm{M}$-sodium azide as preservative and I ml. of the test enzyme solution. After incubation for up to I week at $50^{\circ}$, the tubes were centrifuged and supernatant was removed by pipette until I $.8 \mathrm{ml}$. remained. Approximately $10 \mathrm{ml}$. of distilled water was added, the tubes were recentrifuged, supernatant again removed to the $\mathrm{I} \cdot 8 \mathrm{ml}$. level and the washing repeated three more times. Finally, $4 \mathrm{ml}$. of $0.5 \%$ potassium dichromate in sulphuric acid (Halliwell, 1958) was added and the solution heated in a boiling water bath for $30 \mathrm{~min}$. After dilution with $25 \mathrm{ml}$. water the absorbance of the solution was measured at $6 \mathrm{IO} \mathrm{nm}$. using water as reference. A control curve was constructed using water in place of the enzyme solution and varying the amount of cotton. Very good linearity was obtained for weights up to $2.5 \mathrm{mg}$. the correlation coefficient, $r$, being 0.996 .

\section{Cellulase and hemicellulase using partially modified substrates}

Four types of cellulose were used. Aspen wood, milled in a Wiley mill to pass a 60-mesh screen, was delignified with acidified chlorite (Wise, Murphy \& D'addieco, 1946), freezedried and ground in a ceramic jar on a rotary ball mill for $48 \mathrm{~h}$. Whatman no. I filter paper and also nonabsorbent cotton were similarly milled in a Wiley mill and ball mill. Finally, 6o-mesh Whatman no. I filter paper was swollen with phosphoric acid according to Walseth 
(1952). Aspen hemicellulose was also prepared according to Timell (1967). For assay about $200 \mathrm{mg}$. of substrate dried in vacuo at $55^{\circ}$ was accurately weighed to the nearest $\mathrm{O} \cdot \mathrm{I} \mathrm{mg}$. and incubated at $50^{\circ}$ with $3 \mathrm{ml}$. of $0.2 \mathrm{M}$-acetate buffer $\mathrm{pH} 5.0,5 \mathrm{ml}$. test enzyme solution and $2 \mathrm{ml}$. water. After I to 3 days the residue was collected on tared M-porosity sintered glass funnels, washed with water, dried overnight in vacuo at $55^{\circ}$ and weighed. Values obtained were subtracted from those of controls run concurrently using enzyme solution autoclaved for $20 \mathrm{~min}$. at $12 \mathrm{I}^{\circ}$. Total reducing sugar content of the supernatant was determined by the method of Somogyi (1952) and control values were again subtracted.

Specific mono- and disaccharides were identified by paper chromatography as follows: $2 \mathrm{ml}$. culture supernatant was mixed with $4 \mathrm{~g}$. of wet Rexyn-RG-5o(H+), filtered, evaporated under reduced pressure below $40^{\circ}$ and the residue dissolved in $0.2 \mathrm{ml} .10 \%(\mathrm{v} / \mathrm{v})$ aqueous isopropanol; $5 \mu$ l. quantities were spotted onto Whatman no. I chromatography paper. Alternatively to detect smaller amounts of sugars, $2 \mathrm{ml}$. culture supernatant was evaporated as before and sugars extracted from the residue for $10 \mathrm{~min}$. at $100^{\circ}$ with $5 \mathrm{ml}$. of dry redistilled pyridine (Malpress \& Morrison, 1949). After removing salts by filtration the pyridine was evaporated as before and the residue was dissolved in $0.2 \mathrm{ml}$. water or $10 \%$ (v/v) aqueous isopropanol and $15 \mu \mathrm{l}$. quantities were spotted onto Whatman no. I chromatography paper. Chromatograms were developed for $48 \mathrm{~h}$. by descending chromatography with ethyl acetate:acetic acid:water $(3: I: 3)$ and sugars detected by spraying with aniline phthalate reagent. Chromatograms were also examined under ultraviolet light. Migration distances were measured relative to xylose and recorded as $\boldsymbol{R}_{\mathrm{x}}$ values.

Ultrasonic disruption of cells. Approximately $15 \mathrm{ml}$. culture was chilled in a $30 \mathrm{ml}$. beaker immersed in an ice bath. The fungus was disrupted ultrasonically for $2 \mathrm{~min}$. with a cell disrupter (Branson Instruments Inc., Danbury, Connecticut) at a power setting of 4 . Samples were examined microscopically to confirm that the walls had been extensively ruptured.

Measurement of dissolved oxygen. The oxygen electrode was of the electrochemical galvanic-membrane type (New Brunswick Scientific Co., New Brunswick, New Jersey). Readings in shake culture were taken I min. after the probe had been inserted into the flask and the shaker had been restarted. The probe was sterilized in place for fermenter cultures and readings were recorded continuously.

\section{RESULTS}

\section{Production of CM-cellulase with glucose or glycerol as sole carbohydrate}

Fig. I shows that when cultures were grown on glucose as sole carbohydrate, CMcellulase began to accumulate in the medium at about the time that the carbohydrate became limiting. Ultrasonic disruption of the mycelium suggested that CM-cellulase formed within the hyphae was liberated into the medium within about $\mathrm{to} h$. and modifies our earlier view, derived from less frequent sampling, that CM-cellulase cannot be detected intracellularly at any time (Hulme \& Stranks, 1970). Furthermore, whereas the maximum dry weight increased about threefold when the glucose concentration was raised from 0.1 to $0.5 \%$, cellulase production was increased about 12 -fold. Data from cultures grown on $0.3 \%$ and $\mathrm{I} \cdot 0 \%$ glucose, but not plotted in Fig. I for the sake of clarity also followed this trend. Oxygen limitation may favour the production of CM-cellulase at high mycelial concentrations: the dissolved oxygen level fell only to $90 \%$ of the fully saturated value for cultures grown on $0.1 \%$ glucose but to $50 \%$ for cultures grown on $0.5 \%$ glucose and to near zero for cultures grown on I \% glucose. Variations in $\mathrm{pH}$ were similar in all experiments: from a starting value of 5.5 , the $\mathrm{pH}$ dropped as much as 0.5 units as glucose was consumed and 
then gradually rose to $7 \cdot 5$ to $8 \cdot 0$. Phase-contrast microscopy showed that when glucose was exhausted hyphae gradually became vacuolated and spores were produced. The mould had a similar morphology when grown for 3 to 7 days on 6o-mesh Whatman no. I filter paper in place of $90 \%$ of the glucose, even though the cellulose was never totally consumed. However, in the latter case the presumed slow intake of carbohydrate sustained considerable production of CM-cellulase (about 2400 units/flask) which apparently only occurs during conditions of partial starvation.

Reese and Mandels' medium contained small amounts of yeast extract to provide additional growth factors, but this material might also provide an inducer for synthesis of CM-cellulase. Myrothecium verrucaria is capable of growing without this supplement, but

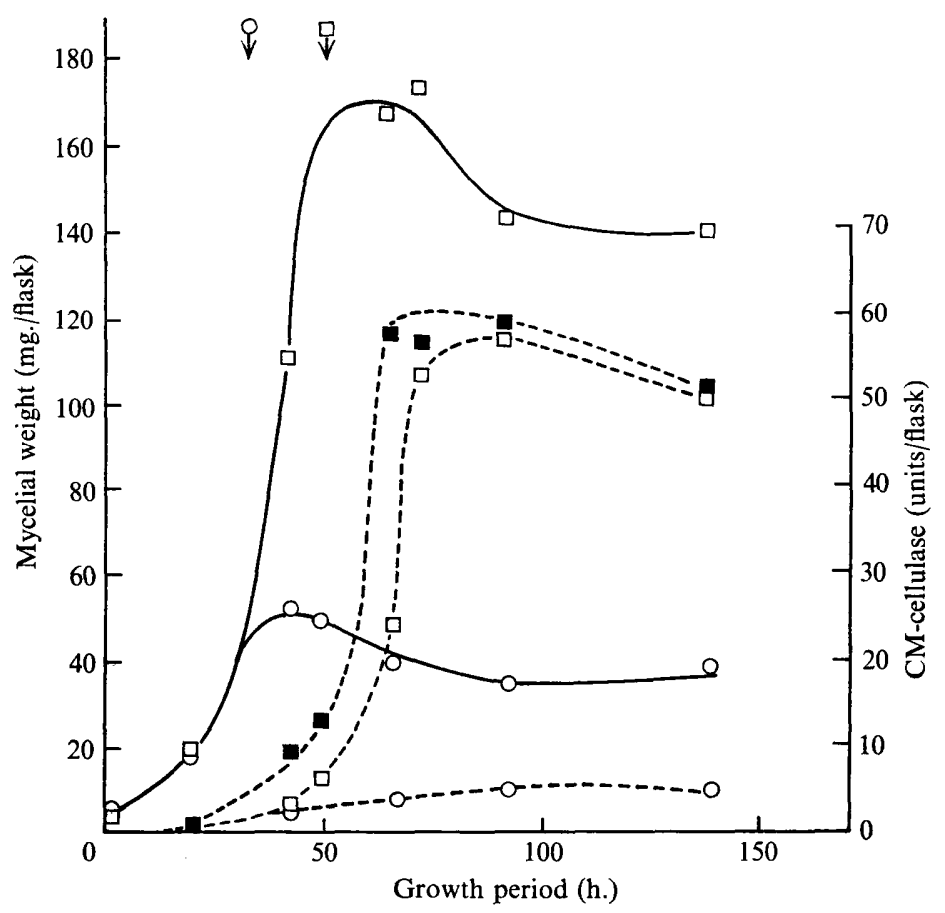

Fig. I. CM-cellulase production from batch cultures of Myrothecium verrucaria growing on basal medium plus $0.1 \%$ glucose $(0)$ or $0.5 \%$ glucose ( $\square$ ( ). Mycelial dry weight —- (mg./flask); CM-cellulase - - - (units/flask). Closed squares are for supernatant of total culture material after sonication. Arrows point out the time of glucose exhaustion from the culture medium.

Table I. CM-cellulase production from batch cultures of Myrothecium verrucaria grown on basal medium plus I \% glucose with $(+)$ or without $(-) 0.01 \%$ yeast extract

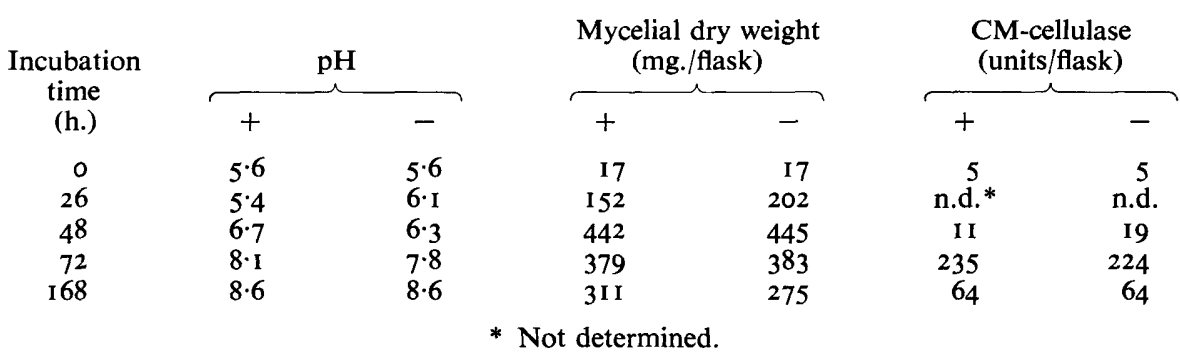


it was usually retained so that micronutrients need not be altered for work with basidiomycetes (to be reported later) which are often heterotrophic for such nutrients as thiamine (Jennison, Newcomb \& Henderson, 1955). Table I shows that yields of CM-cellulase were identical when yeast extract was omitted and the inoculum was a third transfer from media deficient in yeast extract to prevent carry-over of micronutrients, and so it seems unlikely that any inducer was provided by yeast extract.

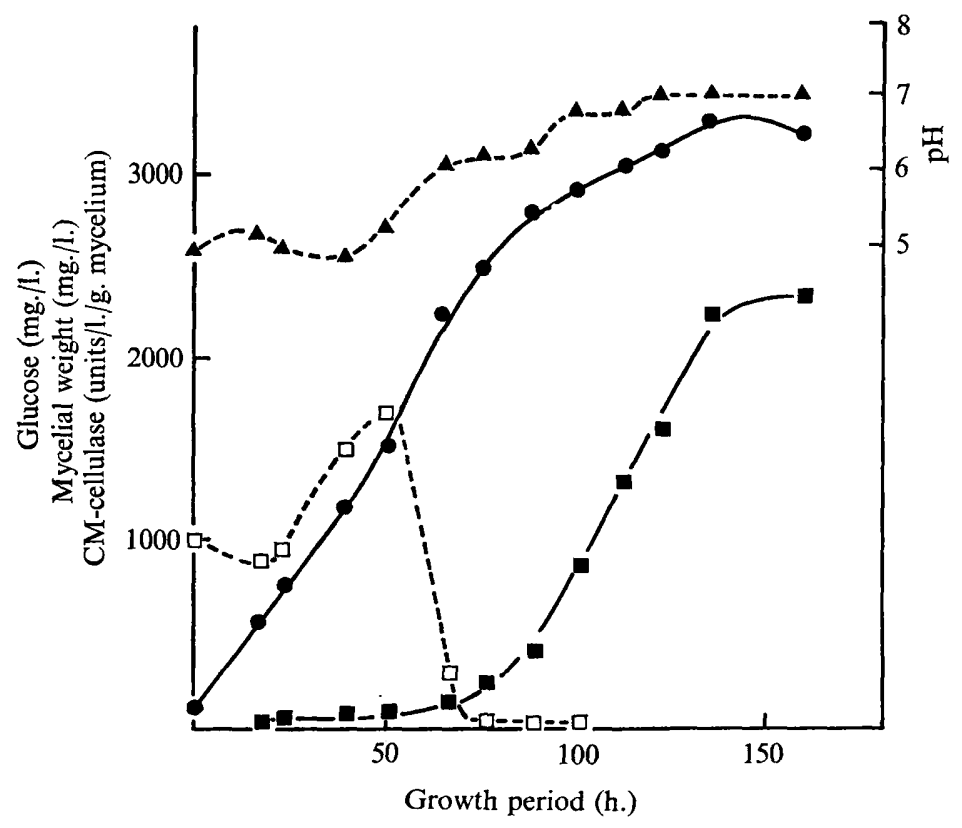

Fig. 2. CM-cellulase production from a 3.31. fermenter culture of Myrothecium verrucaria continuously supplied with basal medium plus $4 \%(\mathrm{w} / \mathrm{v})$ glucose at a dilution rate of $0.3 \% \mathrm{~h} .^{-1}$. The fermenter originally contained basal medium plus $0.1 \%$ glucose and the feed was started after Io h. Mycelial dry weight — (mg./l.); CM-cellulase —— (units/l./g. mycelium); supernatant glucose concentration $\square \ldots \ldots-.-\square(\mathrm{mg} . / \mathrm{l}.) ; \mathrm{pH} \boldsymbol{\Delta} \ldots \ldots$.

After the successful production of CM-cellulase in shake flasks with glucose media, attempts were made to prolong the phase of glucose-limited growth. Cultures in $4 \mathrm{l}$. glass fermenters were allowed to develop normally on a medium containing a low concentration of glucose. When this supply was nearly exhausted a continuous feed of fresh glucose medium was started at a rate sufficient to sustain only a relatively slow accumulation of mycelium. Fig. 2 shows some typical results. When growth rate became regulated by the supplementary feed some sporulation occurred, but the spores often germinated within $24 \mathrm{~h}$. Little if any vacuolation was observed until after $120 \mathrm{~h}$., and even after $160 \mathrm{~h}$. when the experiment was terminated the extent of vacuolation was only moderate. Unfortunately it is not possible to describe these morphological observations in more quantitative terms since the organism develops as small pellets and the nutritional status of each cell depends upon its position in the pellet (Pirt, I966). In the present work pellet size could usually be restricted to $2 \mathrm{~mm}$. mainly by manipulating the degree of blending of the inoculum and the stirring speed of the impeller in the fermenter. In cultures with larger pellets cells were in different phases of development and results were generally erratic.

CM-cellulase production (Fig. 2) was correlated with the organism's growth rate. Yields 
per unit weight of mycelium were low when growth was fast but increased rapidly and linearly when the growth rate was reduced by means of the supplementary feed. The halt in production after $\mathrm{I} 35 \mathrm{~h}$. when $\mathrm{CM}$-cellulase concentrations reached the equivalent of 600 units/shake flask may have been due to mechanical problems: the broth at this stage had become very thick and the stirrer was incapable of maintaining an even dispersion of pellets. A collar of mycelium also began to form at the liquid-air interface.

The previous experiments were repeated using glycerol as carbohydrate source and essentially similar results were obtained (Fig. 3 \& 4). Enzyme yields per unit weight of mycelium were not plotted for batch cultures because later decreases of mycelial weight misleadingly suggested that production of cellulase was still continuing. Morphological observations paralleled those of cultures grown with glucose. One possibly significant difference between cultures grown on glycerol and glucose is that we have not been able to maintain CM-cellulase production in the former for more than about $20 \mathrm{~h}$. and yields have been correspondingly lower. Again though, problems of heterogeneity were encountered.

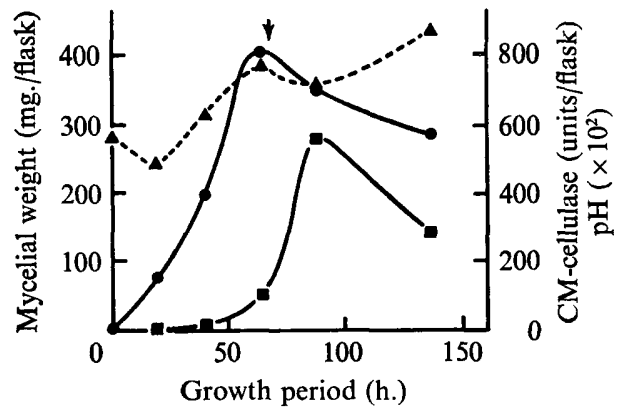

Fig. 3

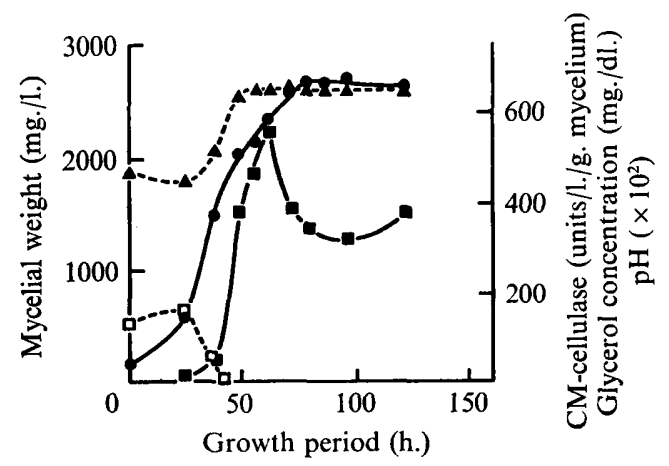

Fig. 4

Fig. 3. CM-cellulase production from batch cultures of Myrothecium verrucaria grown on basal medium plus I \% glycerol. Mycelial dry weight $\bigcirc$ (mg./flask); CM-cellulase $\mathbf{0}-\ldots$ (units/flask); pH $\mathbf{\Delta}$ - . - - A. Arrow points out time of glycerol exhaustion.

Fig. 4. CM-cellulase production from a 3.31. fermenter culture of Myrothecium verrucaria continuously supplied with a feed of basal medium plus $2 \%(\mathrm{w} / \mathrm{v})$ glycerol at a dilution rate of $0.4 \% \mathrm{~h}^{-1}$. The fermenter originally contained basal medium plus $0 . \mathrm{I} \%$ glycerol and the feed was started after Io h. Mycelial dry weight (mg./l.); CM-cellulase _- (units/l./g. mycelium); supernatant glycerol concentration $\square-\ldots-\square$ (mg./dl.); pH $\mathbf{\Delta}-\ldots . .$.

\section{Mechanism of CM-cellulase production}

Results so far indicate that under present conditions ability to form CM-cellulase was acquired during the phase of approximately logarithmic growth. Fig. 5 summarizes data from many cultures of Myrothecium verrucaria grown in fermenters equipped to supply glucose or glycerol continuously and suggests that the amount of CM-cellulase formed per unit weight of cells may partly depend on the duration of growth at the maximum rate before carbohydrate becomes limiting. Scatter is to be expected in these results since parameters such as pellet size are inherently difficult to reproduce and aeration, stirring speed and dilution rate were all varied somewhat. The simple batch-culture experiment summarized in Table 2 further supports our tentative conclusions and minimizes scatter due to variations in culture conditions. The Table also indicates that CM-cellulase is extracellular since ultrasonic disruption of the cells did not increase the final yield of enzyme. 
With regard to release of enzyme from the cells, data of Fig. I suggest that CM-cellulase is gradually liberated from the cells as it is formed rather than being stored and released autolytically. Morphological observations also tend to support this conclusion.

Action of enzyme on various cellulosic substrates

Table 3 shows that supernatant obtained from a culture of Myrothecium verrucaria grown with a slow feed of glucose and containing 7 units of CM-cellulase per $\mathrm{ml}$. was able to depolymerize many types of cellulose as well as hemicellulose; results shown in Table 4

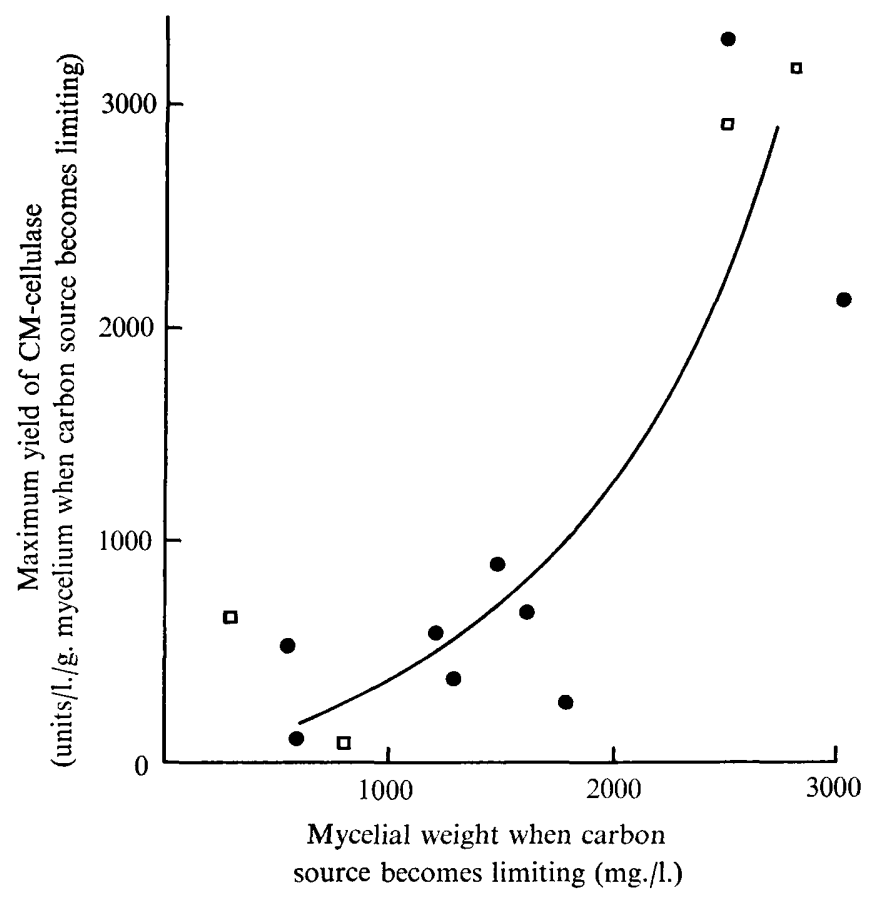

Fig. 5. Relationship between maximum CM-cellulase yield from fermenter cultures of Myrothecium verrucaria grown on a continuous feed of glucose $(\square)$ or glycerol $(\bullet)$ and the mycelial dry weight attained during approximately logarithmic growth.

Table 2. Maximum CM-cellulase yield from shake cultures of Myrothecium verrucaria grown on basal medium and various amounts of glucose

Glucose content
$(\%)$
0.1
0.3
0.5

CM-cellulase yield
in supernatant
(units/flask/g. mycelium)
72
I I 5
$34 \mathrm{I}$

* Not determined.
CM-cellulase yield in supernatant of sonicated culture (units/flask/g. mycelium)

$$
\begin{aligned}
& \text { n.d.* } \\
& \text { n.d. } \\
& 347
\end{aligned}
$$

confirm that both cellulase and hemicellulase were present. This same enzyme complex also contained all the components needed to depolymerize the cellulose in cotton fibres: results of Table 5 demonstrate the progressive solubilization of cotton when incubated with an enzyme solution containing 22 units of CM-cellulase per $\mathrm{ml}$. 
Table 3. Depolymerization of cellulose and hemicellulose by supernatant from a culture of Myrothecium verrucaria grown on glucose

Percentage weight
of substrate made
water soluble

Ball-milled aspen holocellulose

Ball-milled filter paper

Ball-milled cotton

Filter paper swollen with phosphoric acid

Hemicellulose
Percentage weight of substrate recovered as water soluble reducing sugar when calculated as glucose

* Impossible to determine due to extensive water solubility of substrate.

Table 4. Detection of soluble end-products of depolymerization from Table 3 by paper chromatography

Xylose $(1 \cdot 00)^{*}$
Mannose $(0.65)$
Glucose $(0.50)$
Galactose $(0.45)$
Xylobiose $(0.31)$
Cellobiose (0.15)
Xylotriose (0.09)

Holocellulose

Cotton

Swollen cellulose

Hemicellulose

$-v e$
tr $\dagger$
$+v e \ddagger$
$\operatorname{tr}$
$+v e$
$\operatorname{tr}$
$+v e$

-ve

-ve

+ ve

- ve

- ve

- ve

$+\mathrm{ve}$

+ ve

-ve

$-\mathrm{ve}$

+ ve

- ve

-ve

$4 \cdot 0$

I. 6

I. 4

$8 \cdot 6$

$4^{\circ} 0$

* Figures in parentheses are $R_{\mathbf{x}}$ values.

$\uparrow$ Trace clearly seen under ultraviolet light.

¥ With cellulose substrates glucose was always the major component comprising at least $75 \%$ of the total. Control incubations using autoclaved enzyme showed only traces of glucose and no other sugar.

Table 5. Depolymerization of dewaxed cotton by supernatant from a culture of Myrothecium verrucaria grown on glucose

Incubation period

(h.)

60

64

160
Percentage of weight made water soluble

$$
\begin{array}{r}
7 \cdot 8 \\
8 \cdot 2 \\
13 \cdot 8
\end{array}
$$

\section{DISCUSSION}

Myrothecium verrucaria can produce a cellulase complex from glucose or glycerol carbon sources that is capable of depolymerizing substrates ranging from carboxymethylcellulose to dewaxed cotton fibres. Hemicellulases were also produced with these carbon sources as evidenced by the ability of the culture supernatant to depolymerize the hemicellulose fraction in holocellulose and also isolated hemicellulose. Fig. I indicates that most of these depolymerases were produced during the deceleration phase of growth (Mandels, 1965) and were released into the medium after a short lag period. Data of Table 2 and Fig. 5 further suggest that potential ability to form the enzyme increased quickly during the phase of approximately logarithmic growth but was not manifest until the deceleration phase; hence cultures restricted to a low growth rate without being allowed any rapid growth only produced low yields of enzyme. A similar situation is reported to obtain for the synthesis of some antibiotics (e.g. Hockenhull, 1963; Pirt \& Righelato, 1967).

We have consistently found in this work that for cellulase to accumulate in significant 
quantities the growth rate of the mould must eventually be reduced, and this suggests that regulation may in part be effected by the well-known mechanism of catabolite repression (Paigen \& Williams, I970). Studies of production of polygalacturonic acid trans-eliminase by Aeromonas liquefaciens (Hsu \& Vaughn, 1969) and of cellulase by Pseudomonas fluorescens (Yamane et al. 1970) both indicate a similar mechanism of control. The authors of the latter work further suggest from comparisons between growth rate and enzyme levels that regulation of cellulase production during sophorose metabolism may be exceptional. However, semilogarithmic plots of the published growth curves indicate that the logarithmic rate of growth with sophorose was about one half of that with glucose or cellobiose; if this figure is inserted into the listed values for eight sugars (Table I of Yamane et al. 1970), then ability of sophorose to stimulate production of cellulase is correlated with the extent to which the specific growth rate is reduced.

Most of the earlier observations with fungi grown on non-cellulosic media can also be rationalized in terms of stimulation of enzyme production by reduction of the growth rate. Reducing the rate of growth of Trichoderma viride on cellobiose either by decreasing the temperature by $5^{\circ}$ or by providing the substrate as the relatively inaccessible octa-acetate both stimulated cellulase production (Mandels \& Reese, 1960). Other disaccharides such as lactose and sophorose also stimulated cellulase production and were consumed more slowly than cellobiose. Sophorose was unusual, though, in that its effect was highly specific for certain strains of $T$. viride, and although growth restrictions may again enhance cellulase production the underlying mechanism here may well be more complex (Mandels et al. 1962).

Our present data indicate that conditions that are optimal for cellulase production are similar to those required for sporulation and often for antibiotic production, viz. an environment which no longer favours balanced vegetative growth. Indeed we frequently observed that spores appeared at about the same time that cellulase began to accumulate. Such a control mechanism can be readily related to the development of cellulolytic fungi in their natural environment and obviously confers an ecological advantage when cellulose is the only available carbohydrate. However, the apparent need for some rapid growth of laboratory cultures before cellulase production becomes significant is harder to interpret. Perhaps the depolymerization process can only be interpreted here at the cellular level in terms of localized concentrations of enzymes producing localized concentrations of soluble sugars. Whatever the mechanism, it is clear that under some circumstances the entire cellulase complex behaves as a constitutive enzyme and may be produced without cellulose or any of its extracellular breakdown products.

\section{REFERENCES}

Halliwell, G. (1957). Cellulolysis by rumen micro-organisms. Journal of General Microbiology 17, $153-165$. Halliwell, G. (1958). A microdetermination of cellulose in studies with cellulase. Biochemical Journal 68, 605-6ro.

Hockenhull, D. J. D. (1963). Antibiotics. In Biochemistry of Industrial Microorganisms, chap. 7, pp. 227299. Edited by C. Rainbow \& A. H. Rose. London: Academic Press.

Hsu, E. J. \& VAughn, R. H. (1969). Production and catabolite repression of the constitutive polygalacturonic acid trans-eliminase of Aeromonas liquefaciens. Journal of Bacteriology 98, I72-I8I.

Hulme, M. A. \& Stranks, D. W. (1970). Induction and the regulation of production of cellulase by fungi. Nature, London 226, 469-470.

Jennison, M. W., Newcomb, M. D. \& Henderson, R. (1955). Physiology of the wood-rotting basidiomycetes. Growth and nutrition in submerged culture in synthetic media. Mycologia 47, 275-302.

KING, K. W. \& Vessal, M. I. (1969). Enzymes of the callulase complex. In Cellulases and their Applications. Advances in Chemistry Series 95, p. 23. Edited by R. F. Gould. Washington: American Chemical Society. 
MaLPRESS, F. H. \& Morrison, A. B. (1949). Use of pyridine in the deionisation of solutions for paper chromatography. Nature, London 164, 963.

MANDELs, G. R. (I965). Kinetics of fungal growth. In The Fungi, vol. I, chap. 25, pp. 599-612. Edited by G. C. Ainsworth \& A. S. Sussman. New York: Academic Press.

Mandels, M., ParRish, F. W. \& Reese, E. T. (1962). Sophorose as an inducer of cellulase in Trichoderma viride. Journal of Bacteriology 83, 400-408.

MANDELS, M. \& REeSE, E. T. (1960). Induction of cellulase in fungi by cellobiose. Journal of Bacteriology 79, 816-826.

MANDELS, M. \& ReEsE, E. T. (1964). Fungal cellulases and the microbial decomposition of cellulosic fabric. Developments in Industrial Microbiology 5, 5-20.

NeISH, A. C. (1952). Analytical methods for bacterial fermentations. National Research Council of Canada Report 2952, p. 21.

Paigen, K. \& Williams, B. (1970). Catabolite repression and other control mechanisms in carbohydrate utilisation. In Advances in Microbial Physiology, vol. 4, pp. 25I-324. Edited by A. H. Rose \& J. F. Wilkinson. London: Academic Press.

PIRT, S. J. (1966). A theory of the mode of growth of fungi in the form of pellets in submerged culture. Proceedings of the Royal Society B 166, 369-373.

PirT, S. J. \& Righelato, R. C. (I967). Effect of growth rate on the synthesis of penicillin by Penicillium chrysogenum in batch and chemostat cultures. Applied Microbiology 15, I284-I 290.

ReESE, E. T. \& MANDels, M. (1966). $\beta$-Glucanases other than cellulase. Methods in Enzymology vol. 8, p. 608. Edited by E. F. Neufeld \& V. Ginsburg. New York: Academic Press.

SomoGY, M. (1952). Notes on sugar determination. Journal of Biological Chemistry 195, 19-23.

TiMELL, T. E. (1967). Recent progress in the chemistry of wood hemicellulases. Wood Science and Technology I, 45-70.

WALSETH, C. S. (1952). Occurrence of cellulases in enzyme preparations from micro-organisms. Technical Association of the Pulp and Paper Industry 35, 228-232.

Wise, L. E., MURPHY, M. \& D'ADDIECo (1946). Chlorine holocellulose, its fractionation and bearing on summative wood analysis and on studies on the hemicelluloses. Paper Trade Journal 122, I1-43.

Wood, T. M. (1969). The cellulase of Fusarium solani. Biochemical Journal rr5, 457-464.

Yamane, K., SuzuKi, H., Hirotant, M., Ozawa, H. \& Nisizawa, K. (1970). Effect of nature and supply of carbon sources on cellulase formation in Pseudomonas fluorescens var. cellulosa. Journal of Biochemistry 67, 9-18. 